\title{
OFTALMOPLEGIA DOLOROSA
}

\author{
RELATO DE TRES CASOS
}

Francisco Otaviano Lima Perpétuo*

Em 1954 Tolosa $^{7}$ relatou o caso de um homem de 47 anos que apresentou dor no território do nervo oftálmico e oftalmoplegia esquerda progressiva no período de uma semana. O exame mostrou oftalmoplegia completa à esquerda e diminuição do reflexo corneano deste lado; angiografia carotídea esquerda mostrou irregularidades e afilamento da porção superior do sifão carotídeo; o paciente foi submetido a uma craniotomia exploradora falecendo no terceiro dia de pós-operatório. A necrópsia mostrou a presença de tecido granulamatoso dentro do seio cavernoso envolvendo a carótida interna e os nervos adjacentes. O lume arterial não estava afetado mas apenas a adventícia; o afilamento da carótida, visto na angiografia, seria explicado por espasmo ou compressão extrínseca.

Em 1961 Hunt e col. ${ }^{3}$ descreveram 6 casos clinicamente semelhantes. Estes autores ressaltaram a semelhança de seus casos com o de Tolosa e, afastadas outras possíveis causas, acreditam tenham a mesma etiologia. Recuperação após alguns dias ou meses e recurrências após meses ou anos foi a regra geral.

Smith e Taxdal ${ }^{5}$ relataram, em 1965, 5 casos e propuzeram que antes de submeter o paciente a exames complementares mais complicados tais como angiografia e biópsia de cavo faríngeo, fossem administrados corticóides (60 a 80 miligramos de prednisoma $/ 24$ horas) por um periodo de 48 horas, como prova terapêutica. Segundo esses autores as melhoras começam dentro de poucas horas.

Em 1970 Steele e Vasuvat ${ }^{6}$ publicaram sua experiência com 14 pacientes tailandeses, vistos em um período de 13 meses, que relataram história de paralisias recurrentes de nervos cranianos acompanhadas por cefaléia. Os nervos mais constantemente acometidos foram os motores oculares mas o óptico ( 8 casos), o facial (4 casos), o estato-acústico ( 2 casos), o glossofaríngeo ( 3 casos) e o vago ( 2 casos) foram também acometidos. Os autores chamam a atenção para semelhanças clínicas com a síndrome descrita por Tolosa e Hunt, advogando a mesma etiologia para os seus casos. Recurrências foram também comuns.

Em um período de 4 meses (março a julho de 1973) tivemos a oportunidade de acompanhar 3 pacientes com cefaléia localizada e paralisia progressiva de nervos cranianos.

* Professor Assistente da Clínica Neurológica da Faculdade de Medicina da Universidade Federal de Minas Gerais. 


\section{OB SER V A ÇO E S}

CASo 1 - M.G.J., com 20 anos de idade, branca, sexo feminino, admitida no Hospital das Clínicas da Faculdade de Medicina da Universidade Federal de Minas Gerais, em 29-03-1973 (Regsitro 2953). Em janeiro de 1973 a paciente comecou a apresentar cefaléia frontal esquerda, contínua, às vezes acompanhada de vômitos e que respondia aos analgésicos comuns. Ptose da pálpebra superior esquerda ocorreu em um periodo de 3 dias comecando 20 dias antes da admissão. Na mesma ocasião a paciente notou diplopia. A história pregressa não era digna de nota. O exame físico foi normal. Exame neurológico - Oftalmoplegia externa completa à esquerda; pupilas medindo $2 / 2$ milímetros com reflexo mais lento à esquerda. Sensibilidade da face normal. Exame otorrinolaringológico normal. Exames complementares - Hemosedimentação, 27 milímetros na 1. ${ }^{a}$ hora. Prova de tolerância à glicose, normal. Pesquisa de células L.E. negativa. Hemograma, exame de urina, química rotineira de sangue (uréia, creatinina, colesterol, proteinas séricas) normais. Eletrencefalograma: paroxismos lentos na região temporo-occipital esquerda: irregularidade de enchimento e afilamento do sifão carotídeo esquerdo (Fig. 1).
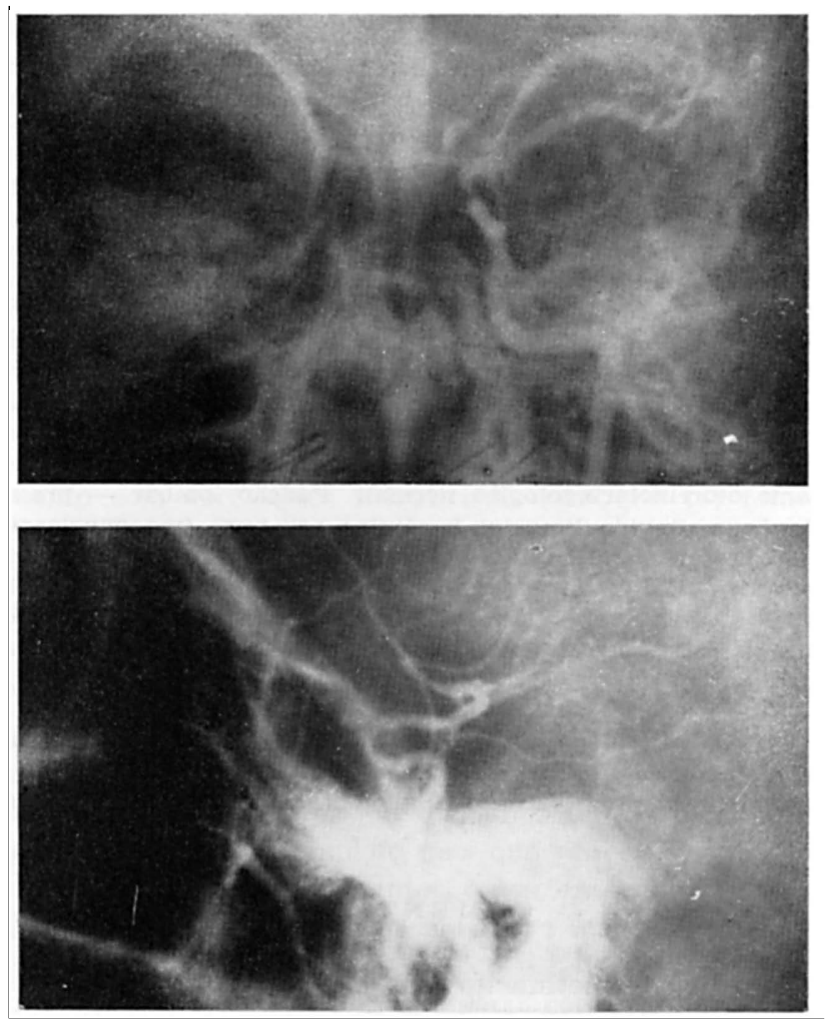

Fig. 1 - Caso 1 (M.G.J.). Angiografia carotidea esquerda mostrando irregularidades no sifão carotídeo com marcado afilamento na porção superior. 
Evoluça $a$ - Foi instituido tratamento com prednisona em dose inicial de 80 miligramas por dia. Melhora progressiva ocorreu começando por alivio da dor aproximadamente no quinto dia de tratamento; pela altura do 20.0 dia de tratamento a paciente encontrava-se completamente assintomática.

Caso 2 - J.E.S., 28 anos de idade, sexo masculino, preto, admitido no Hospital das Clínicas em 21-03-1973 (Registro 2941). Em 1968 o paciente sofreu cefaléia periorbitária esquerda que regrediu espontaneamente em 4 ou 5 meses e nāo foi acompanhada de outra sintomatologia. Trinta dias antes da admissão desenvolveu novamente uma cefaléia periorbitária esquerda estendendo-se à região frontal e temporal. Aproximadamente 10 dias depois ocorreu ptose palpebral esquerda e diplopia. A história pregressa não era digna de nơta. Exame físico normal. Exame otorrinolaringológico normal. Exame neurológico - Paralisia do $3 .^{\circ}$ nervo craniano à esquerda. Pupilas medindo $2 / 4$ milímetros sendo a pupila esquerda pouco reativa à luz. Reflexo corneano diminuido à esquerda. Restante do exame neurológico normal. Exames complementares - Hemosedimentação 20 milímetros na $1 .^{\mathrm{a}}$ hora. Pesquisa de células L.E. negativa. Prova de tolerância à glicose normal. Hemograma, exame de urina, e quimica rotineira de sangue (ureia, creatinina, colesterol, proteinas séricas), normais. Eletrencefalograma: ondas lentas de 4 a 5 ciclos por segundo em ambas as regióes occipitais. Angiografia pela carótida esquerda normal.

Evolução - O paciente foi medicado com prednisona (80 miligramas em 24 horas). Depois de um periodo de 48 horas começou a apresentar melhoras com alivio da dor e díminuição da ptose palpebral. Na ocasião da alta, aproximadamente 40 dias após a admissão, ainda apresentava discreta diplopia ao olhar para a direita.

CASo 3 * - A.M.A., com 18 anos de idade, sexo feminino, branca, admitida no Hospital São Francisco em 13-07-1973. Sua moléstia começou 20 dias antes da admissão com dor supraorbitária à esquerda, intensa e contínua. Aproximadamente 2 dias após notou baixa progressiva na acuidade visual do olho esquerdo, ficando "completamente cega" (sic) deste olho. A visão melhorou progressivamente ao cabo de alguns dias aparecendo então diplopia e ptose palpebral à esquerda. O exame fisico, no dia da admissão, foi normal. Exame neurológico - Paresia do $3 .^{\circ}$ nervo craniano e ptose palpebral à esquerda; reflexo corneano diminuido deste mesmo lado; pupilas isocóricas de diâmetro médio e igualmente reativas à luz; acuidade visual não foi rigorosamente medida mas parecia normal; campo visual de confrontação normal. Exame otorrinolaringológico normal. Punção lombar - pressão inicial 180 milímetros de água, liquido límpido; 3 células por $\mathrm{mm}^{3}$ (mononucleares 100\%); glicose $79 \mathrm{mg} \%$; proteinas $32 \mathrm{mg} \%$. Radiografia do crânio e angiografia carotídea esquerda, normais. Prova de tolerância à glicose normal. Hemosedimentacãa: 11 milimetros após 60 minutos. Química rotineira de sangue (uréia, creatinina, colesterol, proteinas séricas), hemograma e exame de urina normais. Pesquisa de células L.E. negativa.

Evolução - O tratamento com dexametasona (4 $\mathrm{mg}$ IM de $6 / 6$ horas) foi iniciado no dia da admissão. Em 48 horas a paciente relatou melhora da cefaléia e, após 72 horas, melhora progressiva da diplopia. Após 10 dias de tratamento encontrava-se assintomática.

\section{COMENTARIOS}

O quadro com acometimento dos nervos motores oculares unilateralmente e do ramo oftálmico do trigêmio sugere a localização da lesão na

* O autor agradece ao Dr. José Teotônio de Oliveira, neurocirurgião do Hospital São Francisco, a gentileza de lhe ter cedido a observação deste caso. 
região do seio cavernoso. Patologias comuns a essa região tais como aneurisma da carótida interna (que foi o diagnóstico inicial dos dois primeiros casos), tumor infiltrante do faringe ou do seio esfenoidal, cordoma ou adenoma da hipófise foram excluidos pelas radiografias do crânio, pela angiografia, e pelo exame do cavo faríngeo. Arterite temporal foi excluída pela ausência de sintomas generalizados, pela idade dos pacientes e pela hemossedimentação relativamente baixa. Enxaqueca oftalmoplégica é improvável pela ausência de comemorativos anamnésticos pessoais ou familiares e de outros sintomas de enxaqueca tais como náuseas, vômitos e fotofobia. Diabetes mellitus, na qual tem sido relatado acometimento de todos os nervos cranianos exceto o $10^{\circ}$ e o $12 .^{\circ} 1,2,4$, foi excluida pela normalidade da curva de tolerância à glicose. Colagenoses foram excluídas pela ausência de sintomas gerais e pela negatividade da pesquisa de células L.E. A angiografia carotídea do caso 1 mostrou irregularidade e afilamento do sifão carotídeo sendo bastante semelhante à angiografia do paciente de Tolosa ${ }^{7}$ (Fig. 1).

O quadro clínico de nossos pacientes enquadra-se perfeitamente na síndrome descrita por Tolosa ${ }^{7}$ e por Hunt e col. ${ }^{3}$ começando com cefaléia frontal unilateral seguida, dias depois, por oftalmoplegia progressiva e ptose palpebral. A pupila do olho afetado é geralmente de diâmetro médio, com reação lenta à luz. Em dois dos 6 casos descritos por Hunt e col. ${ }^{3}$ houve acometimento unilateral do nervo óptico tal qual ocorreu com nosso terceiro paciente. Um daqueles pacientes, o qual apresentava também discreta proptose teve a órbita e região quiasmática explorados cirurgicamente com resultados negativos, tendo permanecido completamente cego do olho afetado apesar de recuperar os movimentos extra-oculares. Nossos pacientes não têm história de recurrência a não ser pelo fato do paciente J.E.S. (caso 2) ter apresentado cefaléia semelhante, não acompanhada de oftalmoplegia, em 1968, o que poderia ser interpretado como episódio frusto da doença.

O tratamento com corticóides foi iniciado logo que foi feita a suspeita diagnóstica. Os pacientes dos casos 1 e 2 foram tratados com uma dose inicial de 80 miligramas de prednisona/24 horas e a paciente do caso 3 com uma dose de 16 miligramas de dexametasona intramuscular/24 horas, sendo que esta apresentou melhor resultado, com completo alivio da dor em 24 horas tornando-se completamente assintomática após dez dias de tratamento.

Além dos 3 casos relatados neste trabalho tivemos a oportunidade de rever a papeleta de dois outros casos semelhantes, cujo diagnóstico não foi feito na ocasião da internação, e que deixamos de publicar por não terem sido submetidos ao "work-up" completo mas que provavelmente têm a mesma etiologia. O fato de termos visto tantos casos em curto período de tempo sugere que a freqüência desta síndrome em nosso meio deva ser mais elevada do que geralmente se acredita. O diagnóstico é feito por exclusão. A rápida melhora com o uso de corticóides é um dado confirmatório do diagnóstico. Na única necrópsia descrita Tolosa ${ }^{7}$ encontrou uma inflamação crônica inespecífica da dura-mater do seio cavernoso, envolvendo também a adventícia da carótida interna e os nervos adjacentes. A etiologia desse processo é ainda desconhecida. 


\section{R E S U M O}

Após revisão da literatura são relatados 3 casos de polineuropatia craniana. Os quadros clínicos se enquadram na sindrome de "oftalmoplegia dolorosa", relatada por Hunt e col. ${ }^{3}$ e que fora anteriormente descrita por Tolosa ${ }^{7}$. A causa parece ser um processo inflamatório crônico de etiologia não esclarecida situado na dura-mater da base do crânio notadamente do seio cavernoso. Os 3 casos aqui relatados foram vistos, todos, no período de 4 meses, sugerindo que a freqüência desta síndrome em nosso meio deva ser mais elevada do que geralmente se acredita. O prognóstico quanto à recuperação é excelente mas recurrências são freqüentes. $O$ diagnóstico diferencial é discutido.

\section{S U M M A R Y}

\section{Painfull ophtalmoplegia: report of three cases}

Three cases of cranial polineuropathy similar to those published by Hunt and col. ${ }^{3}$ under the name of "Painfull ophtalmoplegia" are reported. The syndrome was first described by Tolosa ${ }^{7}$ in 1954 . The underlying pathology is a chronic inflammatory process which involves the dura-mater of the base of the skull, specially at the cavernous sinus. The three cases here reported were seen over a period of only 4 months, suggesting that this syndrome is more prevalent in Brazil than one might think. The prognosis as to recovery, is good but recurrences are frequent. The differencial diagnosis is discussed.

\section{REFER E N CIAS}

1. COLBY, A. O. - Neurological disorders of diabetes méllitus. Part 1. Diabetes $14: 424,1965$.

2. COLBY, A. O. - Neurological disorders of diabetes méllitus. Part 2. Diabetes 14:516, 1965.

3. HUNT, W. E.; MEAGHER; J. N.; LEFEVER, H. E. \& ZEMAN, W. - Painfull ophtalmoplegia: its relations to indolent inflammation of the cavernous sinus. Neurology (Minneapolis) 11:56, 1961.

4. LAPSON, D. \& AUCHINCLOSS, J. - Multiple symmetric bilateral cranial nerve palsies in patients with unregulated diabetes méllitus. Arch Int. Med. 85:265, 1950.

5. SMITH, J. C. \& TAXDAL, D. S. R. - Painfull ophtalmoplegia: the Tolosa-Hunt syndrome. Amer. J. Ophtal. 61:1466, 1966.

6. STEELE, J. C. \& VASUVAT, A. - Recurrent multiple cranial nerve palsies: a distinctive syndrome of cranial polyneuropathy. J. Neurol. Neurosurg. Psychiat. 33:828, 1970 .

7. TOLOSA, E. - Periarteritic lesions of the carotid siphon with the clinical features of a carotid infraclinoidal aneurysm. J. Neurol. Neurosurg. Psychiat. 17: $300,1954$.

Hospital das Clinicas, $10.0^{\circ}$ andar - Av. Alfredo Balena s/n. $.^{\circ}-30000$ Belo Horizonte, $M G-$ Brasil. 